\title{
Lipoatrophy in Patients with Multiple Sclerosis on Glatiramer Acetate
}

\author{
Catherine M. Edgar, Donald G. Brunet, Paul Fenton, E. Vee McBride, \\ Peter Green
}

\begin{abstract}
Background: Patients with relapsing remitting multiple sclerosis on the disease modifying therapy of glatiramer acetate may be experiencing an adverse reaction of lipoatrophy at the sites of their subcutaneous injections. The purpose of this study was to complete a full examination of the injection site areas for users of glatiramer acetate, and to examine the relationship between lipoatrophy and patient characteristics. Methods: Glatiramer acetate users were identified by means of chart review. Over six months, during regular clinic appointments, assessment included a full examination of injection site areas including visual inspection and manual palpation. Additional patient and clinical characteristics were obtained by means of chart review and patient questioning. Results: Seventy-six patients had been or were current users of glatiramer acetate. Of these, 34 (45\%) had evidence of lipoatrophy in at least one injection site area. All were female, and five had severe, nine had moderate and 20 had mild lipoatrophy. In some cases, lipoatrophy occurred within months of therapy initiation. Case reviews are included for five of the 34 patients, along with photographs of the lipoatrophy, a magnetic resonance image and comments on skin biopsies. Conclusions: Prevalence of lipoatrophy was much higher than expected. Possible reasons for this adverse reaction are explored and suggested treatment recommendations are reviewed. Lipoatrophy can be very disfiguring and is thought to be permanent, and the psychological impact can be significant. It is, therefore, important that patients be aware of the possibility of lipoatrophy, be able to identify it and discontinue injecting in areas where it is identified.
\end{abstract}

RÉSUMÉ: La lipoatrophie chez les patients atteints de sclérose en plaques traités par l'acétate de glatiramère. Introduction: Les patients atteints de la forme rémittente de sclérose en plaques qui prennent de l'acétate de glatiramère, peuvent avoir de la lipoatrophie aux points d'injections souscutanées comme effet secondaire du médicament. Le but de cette étude était de procéder à un examen complet des points d'injections chez les utilisateurs d'acétate de glatiramère et d'examiner la relation entre la lipoatrophie et les caractéristiques des patients. Méthodes: Les utilisateurs d'acétate de glatiramère ont été identifiés par une revue de dossiers. Pendant six mois, ces patients ont subi un examen complet des sites d'injection par inspection visuelle et palpation manuelle au moment de leur visite régulière à la clinique. La revue de dossiers et une entrevue avec les patients ont permis de compléter le profil du patient et ses caractéristiques cliniques. Résultats: Soixante-dix-huit patients utilisaient ou avaient utilisé l'acétate de glatiramère. Parmi eux, 34 (43.6\%) avaient de la lipoatrophie au niveau d'au moins une région servant de point d'injection. Tous étaient des femmes et cinq avaient une lipoatrophie sévère, neuf une lipoatrophie modérée et 20 une lipoatrophie légère. Dans certains cas, la lipoatrophie était apparue en quelques mois après le début du traitement. Les cas de cinq des 34 patientes sont révisés avec photographies et imagerie par résonance magnétique à l'appui, ainsi que des commentaires sur les biopsies cutanées. Conclusions: La prévalence de la lipoatrophie était beaucoup plus élevée que prévue. Nous discutons des raisons possibles de cet effet secondaire et les recommandations de traitement non validées sont révisées. La lipoatrophie peut être très défigurante et elle est considérée comme permanente. Son impact psychologique peut être important. Il est donc essentiel que les patients soient prévenus qu'ils peuvent présenter de la lipoatrophie et qu'ils puissent la reconnaître et cesser les injections dans les régions atteintes.

Can. J. Neurol. Sci. 2004; 31: 58-63

Multiple sclerosis (MS) is a chronic inflammatory demyelinating disease of the central nervous system. The most common form of the disease is relapsing-remitting MS (RRMS) where patients experience multiple exacerbations, or "relapses" over time. There are a number of proven treatments available for RRMS, one of them being glatiramer acetate. Given on a daily basis by subcutaneous injection, it has shown to reduce annualized relapse rate by $32 \% .{ }^{1}$ Despite its claimed excellent adverse event profile ${ }^{1}$ there is increasing concern with skin reactions and the occurrence of lipoatrophy with the use of glatiramer acetate. ${ }^{2}$ As described in the 1995 pivotal trial, "The most commonly recognized adverse event was a localized injection-site reaction consisting of mild erythema and induration, which sometimes persisted for several days. It was observed at least once during 730 days of treatment in $90 \%$ of the copolymer 1-treated patients". ${ }^{1}$

From the MS Clinic, Kingston General Hospital and Department of Medicine, Queen's University, (CME, DGB, EVM); Department of Radiology, Kingston General Hospital and Queen's University, (PF), Kingston, Ontario; and Department of Dermatology, University of Ottawa, Ontario (PG), Canada.

RECEIVED APRIL 1, 2003. ACCEPTED IN FINAL FORM JULy 10, 2003.

Reprint requests to: Cathy Edgar, MS Clinic, Connell 7, Kingston General Hospital, 76 Stuart Street, Kingston, Ontario K7L 2V7 Canada 
Lipoatrophy, described as loss of subcutaneous fat, can occur with the use of intradermal or subcutaneous injection medications including corticosteroids, insulin, vasopressin, human growth hormone, iron dextran, diphtheria-pertusustetanus immunization and antihistamines. The mechanism is probably different for each drug. ${ }^{3}$ We have noted in the outpatient clinic setting that patients who are on glatiramer acetate for treatment of their RRMS are experiencing lipoatrophy at their injection sites. This can occur over a short period of time after initiation and it can occur in multiple sites. It does not necessarily seem to be related to long-term use of subcutaneous injections in the same location since most patients are very diligent about rotating their injection site areas right from the start of treatment. Patients need to be educated at initiation of treatment that they must observe their injection sites for lipoatrophy and discontinue injecting into the site if lipoatrophy occurs. Lipoatrophy is thought to be permanent and can be disfiguring.

The purpose of this study was to complete a full examination of the injection site areas for patients who currently were, or had ever been, on glatiramer acetate for treatment of their RRMS, and to examine the relationship between presence of lipoatrophy and a number of patient characteristics.

\section{Methods}

The MS Clinic at Kingston General Hospital in Kingston, Ontario follows approximately 600 patients with MS on a regular basis. It is an outpatient clinic that approaches MS care by means of a multidisciplinary team approach. The neurologist and the nurse coordinator assess all patients and, if indicated, the occupational therapist and physiotherapist also assess the patient.

Patients come to their clinic assessments from a large geographical area of southeastern Ontario, with a radius of up to 250 kilometers. The number of patients on immunotherapy for RRMS is approximately 200.

All active patients who are on glatiramer acetate or have ever been on glatiramer acetate were identified by means of chart review. Over a six-month period, at their regular follow-up clinic appointments, the clinic (nurse) coordinator included in her nursing assessment a full examination of all injection site areas including visual inspection and manual palpation. Skin changes were subjectively assessed but atrophy was not formally measured. This is a limitation of this study. An estimate by eye and touch only was done by the nurse coordinator. Assignment of severity included subjective designation based on surface area affected, number of areas in one injection site location, number of overall injection site areas affected, length of time on the therapy and stature of the patients. For example "mild" would include patients with one to four areas of atrophy no less than $3 \mathrm{~cm}$ in diameter in one or two areas of injections and approximately $1 \mathrm{~cm}$ in depth. If an area was questionable it was not counted. "Moderate" included greater than four areas of atrophy greater than $3 \mathrm{~cm}^{2}$ and less than $10 \mathrm{~cm}^{2}$ in multiple injection sites. If the patient was slight in stature (thin) the same area and number would be estimated as severe being a far larger percentage of total subcutaneous fat. An example of moderate severity would be Case \#5. A designation of "severe" would include very large areas of depressions greater than $10 \mathrm{~cm}$ square and greater than $1.5 \mathrm{~cm}$ depth in at least two areas plus multiple smaller areas in all injection sites used. An example of severe is Case \#4. Often, for the moderately and severely affected, the

Table: Characteristics of Entire Sample and of those With and Without Lipoatrophy

\begin{tabular}{|c|c|c|c|c|}
\hline Characteristic & $\begin{array}{l}\text { Sample } \\
n=76\end{array}$ & $\begin{array}{l}\text { Lipoatrophy } \\
\mathrm{n}=\mathbf{3 4}\end{array}$ & $\begin{array}{l}\text { Without Lipoatrophy } \\
\mathrm{n}=42\end{array}$ & p-value* \\
\hline \multicolumn{5}{|l|}{ Age in years } \\
\hline Range & $29-64$ & $30-64$ & $29-57$ & \\
\hline \multicolumn{5}{|l|}{ EDSS } \\
\hline Range & $0-5.5$ & $1-5.0$ & $0-5.5$ & \\
\hline Mean (SD) & $2.5(1.5)$ & $2.5(1.1)$ & $2.5(1.7)$ & .790 \\
\hline Range & $21-257$ & $21-257$ & $27-250$ & \\
\hline Mean (SD) & $92.2(58.5)$ & $97.1(63.2)$ & $88.3(54.9)$ & .518 \\
\hline \multicolumn{5}{|c|}{ Time on glatiramer acetate in months } \\
\hline Range & $1-62$ & $7-54$ & $1-62$ & \\
\hline Mean (SD) & $25.3(14.1)$ & $28.2(13.8)$ & $22.8(14.0)$ & .098 \\
\hline \multicolumn{5}{|l|}{ Gender } \\
\hline Slight & $26(34.2 \%)$ & $15(44.1 \%)$ & $11(26.0 \%)$ & \\
\hline Medium & $37(48.6 \%)$ & $14(41.2 \%)$ & $23(54.5 \%)$ & \\
\hline Large & $13(17.1 \%)$ & $5(14.7 \%)$ & $8(19.0 \%)$ & .261 \\
\hline
\end{tabular}

* p-value is based on the two-sample t-test for continuous data and the Chi-square test for categorical data

EDSS $=$ Expanded Disability Status Scale $; \mathrm{SD}=$ standard deviation 
areas are not circular, appearing more like a valley or trough and are very patchy and uneven with multiple areas of lipoatrophy running into one another. Further questioning at the time or by telephone was done to obtain information on injection site reactions, stature, hair colour and skin sensitivity, as well as use of the autoject device. Because the majority of the first seven patients identified in our sample had red or blonde hair, were slight in stature and stated they had sensitive skin, these additional characteristics were selected for investigation. Documentation of skin sensitivity was anecdotal and based on patient perception, which was another limitation to this study. It should be noted also that the clinic coordinator examines all patients seen on other immunotherapies so it is known how many patients on other subcutaneous immunotherapies for MS have lipoatrophy. Although these assessments are not blinded and can not be used as strict controls, lipoatrophy seldom occurs with interferon treatment. The characteristics of those with and without lipoatrophy were compared using the two-sample t-test for the continuous data (age, duration of MS, time on glatiramer acetate and Expanded Disability Status Scale) and Chi-square analyses for the categorical data (gender, hair colour and stature).

\section{RESULTS}

The chart review produced 76 patients with RRMS who were currently, or had been, on glatiramer acetate. The Table contains the characteristics of these patients. The majority was female (86.8\%) and all were Caucasian, mostly of European decent. Forty-four $(57.9 \%)$ reported site reactions all or most of the time. Of the 76, $34(44.7 \%)$ patients had evidence of mild, moderate or severe lipoatrophy in at least one injection site area. Table 1 also contains the characteristics of those with lipoatrophy. All were female, and five $(14.7 \%)$ had severe, nine $(26.5 \%)$ had moderate and $20(58.8 \%)$ had mild lipoatrophy, and all reported site reactions all or most of the time. Their ages ranged from 30 to 64, mean duration was just over eight years, and Expanded Disability Status Scale scores at the time of examination ranged from 1 to 5. Concomitant medications were noted and there was no obvious connection. Time on glatiramer acetate therapy ranged from seven months to 54 months. Table 1 also contains characteristics of those without lipoatrophy. Although they had no lipoatrophy, $10(23.8 \%)$ reported that they always experienced site reactions, $7(16.7 \%)$ reported a reaction initially and $19(45.2 \%)$ reported that they never had site reactions. This information was unknown for another $6(14.3 \%)$. There were no significant differences between those with and without lipoatrophy for any of the continuous variables, although differences in time on glatiramer acetate approached significance $(\mathrm{p}=.098)$. There were significant differences in the proportion of females and males, and those with fair or red hair, between the groups.

Of the 34 patients with lipoatrophy, 12 have discontinued therapy. Lipoatrophy and skin abnormalities were the most common reason $(33 \%)$ for discontinuing treatment or nonadherence with glatiramer acetate in the MS Clinic. ${ }^{4}$ In this sample lipoatrophy was more common and more significant on thighs and arms. Mancardi ${ }^{5}$ and Drago ${ }^{3}$ also found it much more prevalent in the arms and thighs. As a result of the examination, three patients were referred to a dermatologist for further assessment and skin biopsy. Two were referred for magnetic resonance imaging (MRI) examination of the most affected areas of lipoatrophy. It is noteworthy that we have only been able to identify three patients on subcutaneous interferon who have developed lipoatrophy out of a larger sample size over a longer period of time. Several patients are described in more detail below.

\section{Case reports}

\section{Case \#1}

This 51-year-old female had been on therapy for 45 months. She described her injection site reactions as "every one like a bee sting", a red area with raised white swelling in the centre. Severe lipoatrophy was noted as all injection site areas were involved and multiple areas of lipoatrophy were seen in abdominal and thigh sites. The arm sites were not being used due to pain. She is slight in stature (wt $-55 \mathrm{~kg}$, ht $-157 \mathrm{~cm}$ ) therefore the "loss of fat" was more significant in the fact that she was "running out of areas to inject". Patient reported a decrease in self-esteem and had poor self-image. The lipoatrophy is thought to be permanent, and the dermatologist could offer no specific treatment.

\section{Case \#2}

This 40-year-old female describes her injection site reactions "like a bee sting". Therapy had been initiated a little over three years ago. All injection sites were affected. She had discontinued using the upper outer arm injection site areas approximately 18 months previously due to lipoatrophy and painful injections. Magnetic resonance image examination of the most affected arm showed significant thinning of subcutaneous fat in a focal distribution. The underlying musculature was uninvolved. Skin

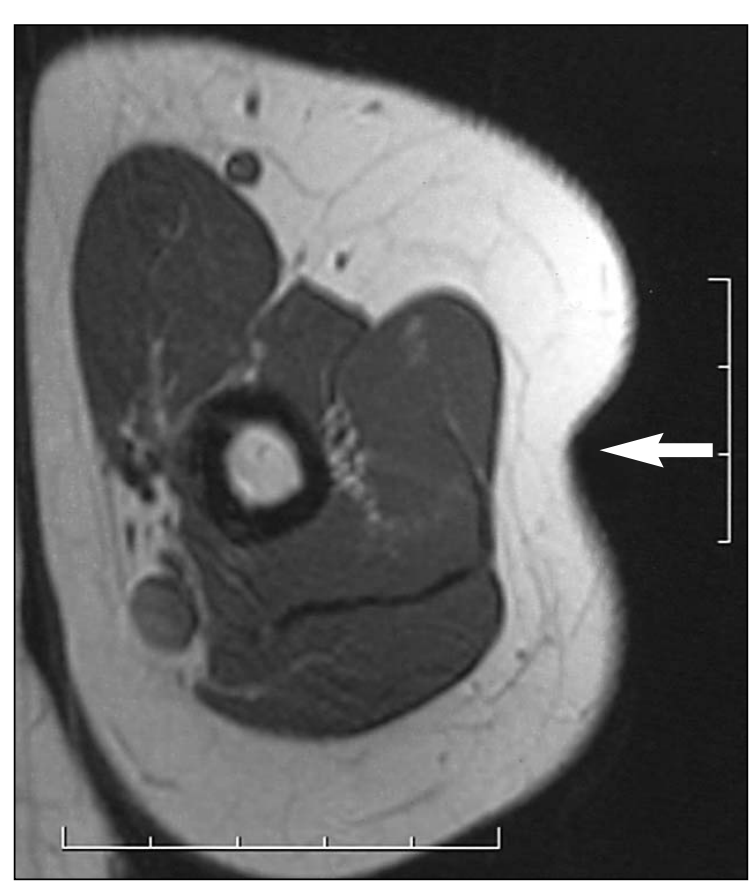

Figure 1: Case \#2 - MRI of right upper arm, posterior aspect 


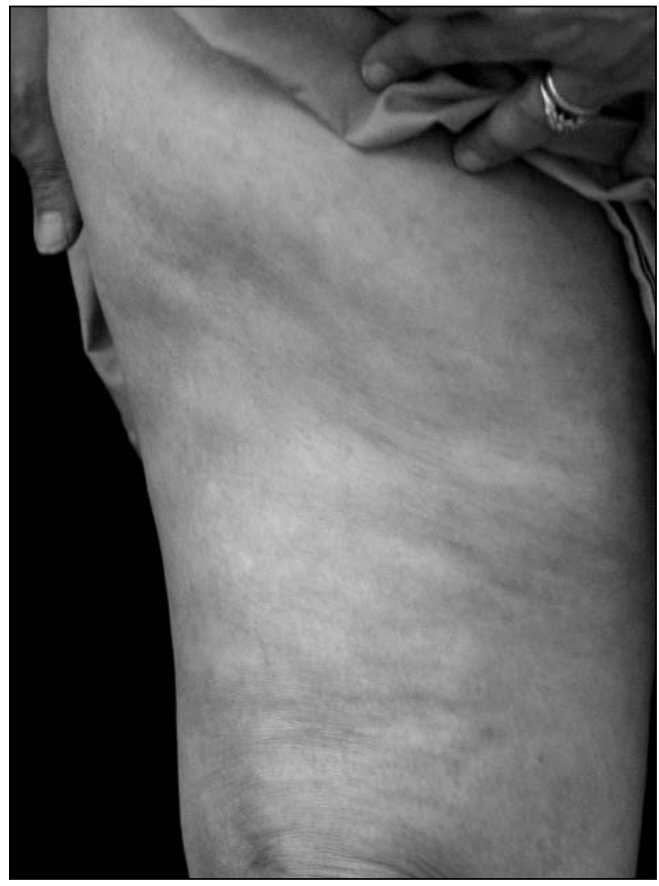

Figure 2: Case \#4 - Anterior right thigh, large area of lipoatrophy

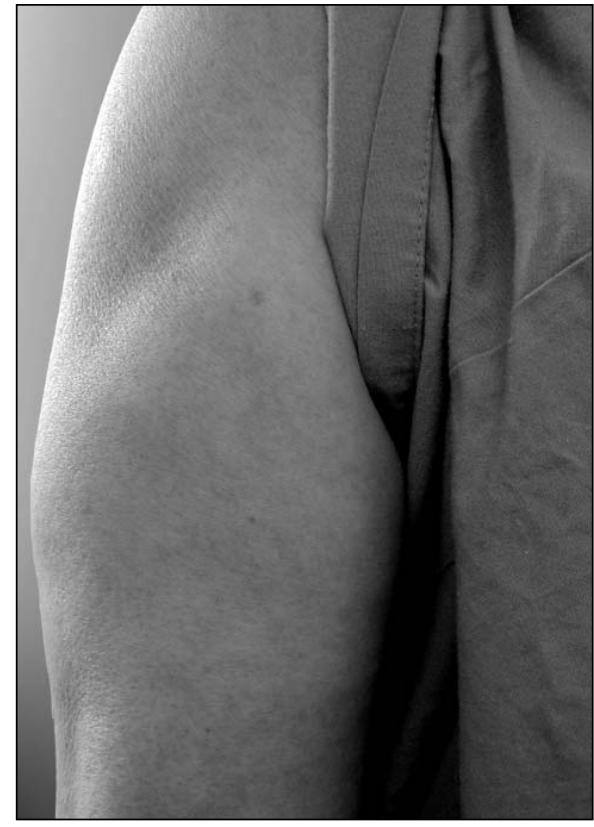

Figure 4: Case \#5 - Posterior aspect of left upper arm

biopsy was not done on the arm sites because she had not been injecting in those areas for over 18 months, so the biopsy was taken from the abdominal site where she was still injecting. Skin biopsy showed normal immunofluorescence and no inflammatory infiltrate. The surface area of lipoatrophy on the arms over the year and a half while not injecting did not decrease and does seem to be permanent. Figure 1 shows the MRI image of the thinning of subcutaneous fat distribution.

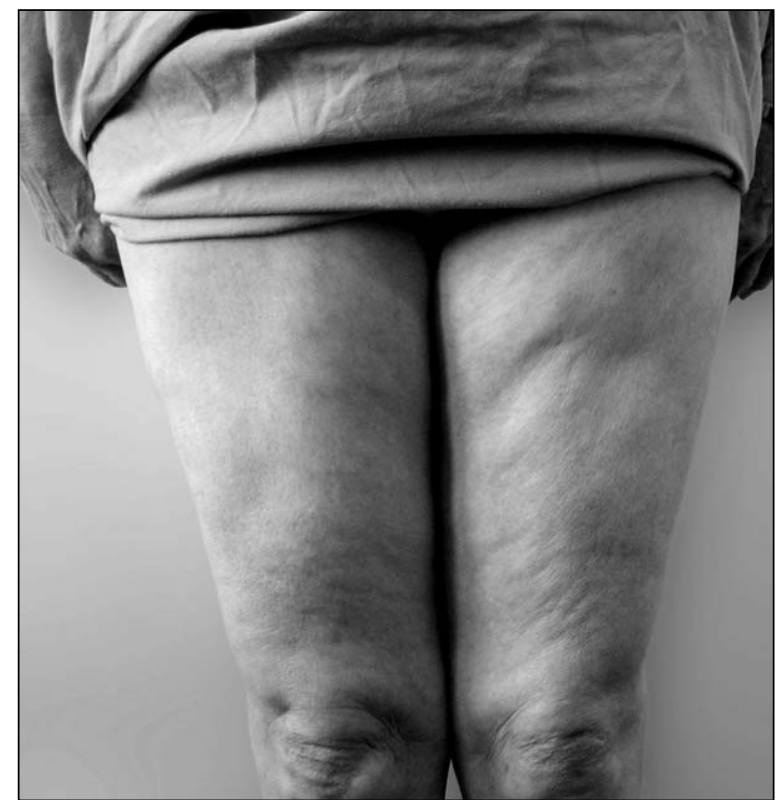

Figure 3: Case \#5 - Anterior thighs, multiple uneven skin depressions

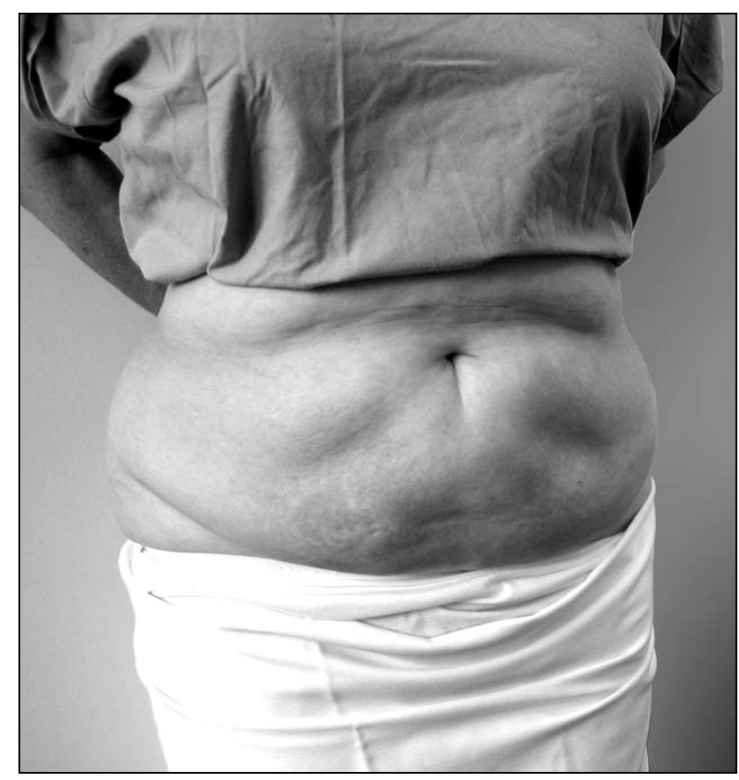

Figure 5: Case \#5 - Lipoatrophy, lower abdomen at sites of injection

\section{Case \#3}

This 48-year-old female has been on glatiramer acetate for two years and six months. Mild areas of lipoatrophy were identified on both thighs at injection sites. Magnetic resonance image examination reported nonspecific findings. Skin punch biopsy also was normal. She has severe fatigue and has chosen to continue on therapy using the abdominal and buttock injection site areas only, which are not affected. 


\section{Case \#4}

This 52-year-old female after two years of therapy has developed significant areas of fat loss in both thighs and abdomen and to a lesser degree mild lipoatrophy in the upper outer buttock sites. She describes injection site reactions like a "hive", yet not with every injection. When examined by the clinic coordinator, she did not know she had lipoatrophy and was quite distressed on realizing these areas were related to her injections and probably permanent. Figure 2 shows the lipoatrophy in the right thigh.

\section{Case \#5}

This 57-year-old female had been on glatiramer acetate from April 2000 to December 2001. Due to multiple areas of lipoatrophy in both thighs, both arms, abdomen and, to a lesser degree buttocks, she was advised to discontinue. After discontinuing this treatment she noted gradual increase in the area of atrophy especially across her right thigh. Figures 3-5 show the areas of lipoatrophy on her thighs, arms and abdomen approximately 10 months after discontinuing glatiramer acetate.

\section{Discussion}

There may be multiple mechanisms influencing the development of lipoatrophy in patients on glatiramer acetate. The assumption that patients are not rotating their injection sites does not seem to be one of the factors. Most patients do rotate to most sites on a regular basis, although they may only use two or three spots in each area while rotating their sites. The arm sites tend to be discontinued most often because it is painful and awkward to use even with the autoject device.

There may be more than one mechanism causing this adverse reaction. We believe that the most significant of three possible mechanisms is the localized "allergic" reaction at the site of the injection, experienced by all of these patients. The reactions are hard to quantify and measure because they vary in size, severity and frequency. For example one patient who had been on treatment over 18 months experienced a reaction she described as a raised white area circled by redness which she measured as $12.5 \mathrm{~cm} \times 17.5 \mathrm{~cm}$ which lasted up to 24 hours. We believe, like Hwang et al, 6 that this "local immune injection reaction" is in some way responsible for injuring the subcutaneous fat.

The second mechanism that may have an influence is the idea of mechanical injury over time. Drago ${ }^{3}$ refers to the acupuncture effects of injections over time. Some of our patients have been on glatiramer acetate over four years and we are just now identifying mild lipoatrophy. It is thought by some that this "acupuncture lipoatrophy heals spontaneously" 3 and therefore may not be permanent. The third possible mechanism is a delayed mechanism of hypersensitivity or inflammation as described by Drago, ${ }^{3}$ yet two histological specimens examined failed to reveal an inflammatory response, nor were biopsies helpful in elucidating an explanation for the clinical findings. The punch biopsies looked at skin, including superficial and deep dermis which lacked an inflammatory response at the time of biopsy. Fat was not examined as the punch biopsies would not look that deep. Although there was a higher percentage of fair/red haired patients who developed lipoatrophy, it is not known if this has any significance. These patients did not necessarily self-report sensitive skin. The use of the autoject did not seem to contribute to lipoatrophy. Most patients do use the autoject device so technique was not an issue and it allows patients to self-inject in all areas.

The patient did not usually identify areas of lipoatrophy. In most cases it was identified by the clinic coordinator during her objective examination by visual inspection and manual palpation of all injection site areas used. However, it was occasionally noted by a family member. Two patients have subjectively reported that, after discontinuing glatiramer acetate, their mild lipoatrophy seemed to be lessening. Therefore it would be important to identify it as soon as it starts occurring.

\section{Suggested treatment recommendations}

It is of great importance to keep the subcutaneous skin healthy, especially when treatment can begin as a young adult and is expected to be long term. Patients should be aware that lipoatrophy can be a side effect of glatiramer acetate treatment and is a relatively common occurrence. Regular supervision and follow-up of treatment should include visual examination and manual palpation of all injection site areas and a general inspection of the health of the skin. In addition, the patient can be taught to do a self-inspection of their injection sites at the same time as a monthly self breast examination. The selfexamination should also include visual inspection while undressed in front of a mirror, and manual palpation of all sites used. If areas of lipoatrophy are noted, no further injections should be given in these sites. There should be some consideration that if the areas are identified early they may lessen, although there does not seem to be much proof of this. At the very least, early identification and avoidance of affected sites would stop progression of lipoatrophy.

Extra caution should be given to patients experiencing localized inflammatory site reactions commonly described by the patient as redness with a raised white area in the middle which can last up to 24 hours. For patients who experience this side effect and choose to continue treatment, the abdominal injection site area seems to be the least affected. Since lipoatrophy can be disfiguring, thought to be permanent and can affect a person's self image, self respect and self confidence, it needs to be identified as soon as it starts occurring and monitored carefully.

To lessen site reactions, it may be possible to place ice on the injection site for five minutes before and five minutes after injection. One could speculate that if the acute localized inflammatory reaction could be reduced, the occurrence of lipoatrophy would be less. In addition, we recommend that teaching materials and the product monograph for glatiramer acetate include lipoatrophy as a common occurrence. Teaching materials could include illustrations of potential skin problems.

Further research is needed to know whether this occurrence truly is permanent, and the nature of the specific cause. Exploring the possibility of blocking the localized inflammatory reaction is a need for further study, in that the damaging effects to the subcutaneous tissue could be lessened. There is also a need for investigation into the possibility that damaged subcutaneous tissue may decrease absorption and, therefore, efficacy.

The fact that lipoatrophy affected only females compares with the literature. All but one reported case (Mancardi ${ }^{5}$ ) are female. In addition, it is unknown as to the sex of the one case referred to by Wolinsky ${ }^{7}$ in his editorial on the 1995 pivotal trial 
suggesting there was "a single occurrence of focal lipoatrophy at injection sites noted in the trial". The majority of females were unaware they had lipoatrophy until noted by a health professional or family member. This leads one to question if there might be a hormonal basis or are there skin structure differences between males and females? Is the male subcutaneous fatty tissue less fragile in some way than females? Does a smaller stature and thinness have any significance?

There is also a need for research into the psychological impact of lipoatrophy. Multiple sclerosis patients already experience significantly reduced quality of life as compared to their peers ${ }^{8,9}$ in most domains of the Medical Outcomes Trust 36item Health Survey (SF-36). ${ }^{10}$ Lipoatrophy is physically disfiguring and may adversely affect quality of life domains such as social functioning, role emotional functioning and mental health. Finally, further research could examine the use of the autoject device, although there was not a strong connection in this study.

\section{Conclusions}

The prevalence of lipoatrophy in patients on glatiramer acetate treatment for RRMS is much higher than expected. In this study it approaches $45 \%$ (34/76). It only occurred in females and it can be very disfiguring and permanent. The psychological impact can be significant. It is very important that patients be aware of the possibility of lipoatrophy, be able to identify it and discontinue injecting in areas where it is identified. In some instances of severe lipoatrophy with multiple sites affected, discontinuation of treatment may be indicated.

\section{REFERENCES}

1. Johnson KP, Brooks BR, Cohen JA, et al. Copolymer 1 reduces relapse rate and improves disability in relapsing-remitting multiple sclerosis. Neurology 1995;43:1268-1276

2. Drago F, Rongioletti F, Battifoglio ML, Rebora A. Localized lipoatrophy after acupuncture [letter]. Lancet 1996;347:1484.

3. Drago F, Brusati C, et al. Localized lipoatrophy after glatiramer acetate injection in patients with remitting-relapsing multiple sclerosis. Arch Dermatol 1999;138:1277-1278.

4. McBride EV, Brunet DG, Edgar CM. Nonadherence to immunmodulation in multiple sclerosis. Int J MS Care 2002;4:85.

5. Mancardi GL. Localized lipoatrophy after prolonged treatment with copolymer-1. J Neurol 2000;247:220-221.

6. Hwang L, Orengo I. Lipoatrophy associated with glatiramer acetate injections for the treatment of multiple sclerosis. Cutis 2001;68:287-288.

7. Wolinsky JS. Copolymer-1 a most reasonable alternate therapy for early relapsing-remitting MS with mild disability. Neurology 1995;45:1245-1247.

8. Brunet DG, Hopman WM, Singer MA, Edgar CM, MacKenzie TA. Measurement of health-related quality of life in multiple sclerosis patients. Can J Neurol Sci 1996;23:99-103.

9. Hopman WM, Coo H, Brunet DG, Edgar CM, Singer MA. Longitudinal assessment of health-related quality of life (HRQL) of patients with multiple sclerosis. Int J MS Care 2000;2:1520,26 .

10. Ware JE. SF-36 Health Survey Manual and Interpretation Guide. Boston, Massachusetts: The Health Institute, New England Medical Centre, 1993. 